\title{
The potential of $\mathrm{hBN}$ nanoparticles as friction modifier and antiwear additive in engine oil
}

\author{
Muhammad Ilman Hakimi Chua Abdullah ${ }^{1}$, Mohd Fadzli Bin Abdollah ${ }^{1,2, a}$, \\ Hilmi Amiruddin ${ }^{1,2}$, Noreffendy Tamaldin ${ }^{1,2}$ and Nur Rashid Mat Nuri ${ }^{3}$ \\ 1 Faculty of Mechanical Engineering, Universiti Teknikal Malaysia Melaka, Hang Tuah Jaya, 76100 Durian Tunggal, Melaka, \\ Malaysia \\ ${ }^{2}$ Centre for Advanced Research on Energy, Universiti Teknikal Malaysia Melaka, Hang Tuah Jaya, 76100 Durian Tunggal, \\ Melaka, Malaysia \\ 3 Faculty of Engineering Technology, Universiti Teknikal Malaysia Melaka, Hang Tuah Jaya, 76100 Durian Tunggal, Melaka, \\ Malaysia
}

Received 19 January 2015, Accepted 25 May 2015

\begin{abstract}
An experimental investigation was conducted to investigate the potential of hexagonal boron nitride $(\mathrm{hBN})$ nanoparticles as friction modifier and antiwear additive in engine oil. In this study, an optimal composition (0.5 vol.\%) of $70 \mathrm{~nm}$ hBN nanoparticles was dispersed in SAE $15 \mathrm{~W}-40$ diesel engine oil by sonication technique. Sample was stabilized using 0.3 vol.\% oleic acid as a surfactant. The tribological test was performed using a four-ball tribometer. Surface morphology and its chemical composition were carried out using a profilometer, Scanning Electron Microscopy (SEM) and Energy-dispersive X-ray Spectroscopy (EDX). It was found that the optimized nano-oil could reduce the coefficient of friction and increase wear resistance, as compared with conventional diesel engine oil. Some adhesive and abrasive wear types were identified as predominant wear mechanisms.
\end{abstract}

Key words: Lubricant / friction / wear / boron nitride

\section{Introduction}

The current capability of nanoparticles, used as a lubricating oil additive to improve the performance of diesel engine oil, still has not yet been extensively explored. Previous studies have reported that using copper $(\mathrm{Cu})$ nanoparticles as an oil additive can improve the anti-wear, load-carrying, and friction-reduction performance of SJ 15W-40 gasoline engine oil [1]. This was in agreement with several other authors' work that used nanoparticles consisting of zirconia/silica $\left(\mathrm{ZrO}_{3} / \mathrm{SiO}_{2}\right)$ composite, copper oxide $(\mathrm{CuO})$, titanium oxide $\left(\mathrm{TiO}_{2}\right)$, and nano-diamond as oil additives [2-4]. Furthermore, the addition of a low concentration of nanoparticles (between $0.2 \%$ and $3 \%$ vol.) into the lubricating oil was sufficient to improve tribological properties [5]. Qiu et al. [6] found that a concentration of $\mathrm{Ni}$ nanoparticles, of between 0.2 and $0.5 \%$, provided the best antiwear and friction-reduction behaviour. Besides, Tao et al. [7] demonstrated that 1 vol.\% was the optimum concentration of diamond nanoparticles in paraffin oil. Friction-

\footnotetext{
${ }^{a}$ Corresponding author: mohdfadzli@utem.edu.my
}

reduction and antiwear behaviours are dependent on the characteristics of nanoparticles, such as size, shape, and concentration. The size of nanoparticles is mostly in the range of 2 to $120 \mathrm{~nm}$ [8-10]. A variety of mechanisms have been proposed to explain the lubrication enhancement of the nanoparticle-suspended lubricating oil (i.e. nanooil), including the ball bearing effect, protective film, mending effect and polishing effect [11]. Chiñas-Castillo et al. [12] investigated the action mechanism of colloidal solid nanoparticles in lubricant oils. Their study showed that in thin film contacts, colloid nanoparticles penetrate elastohydrodynamic (EHD) contacts, mainly by a mechanism of mechanical entrapment. Chen et al. [13] performed studies on a wide range of colloid solid nanoparticles using a four-ball tribotester. Their results showed that the deposition of tribochemical reaction products, produced by nanoparticles during the friction process, can result in an antiwear boundary film, and decrease the wear rate. Qiu et al. [6] also reported that the tribological mechanism deposited a film at the contacting region, which prevented direct rubbing of the surfaces and greatly reduced the frictional force between the contacting surfaces. 
M.I. Hakimi Chua Abdullah: Mechanics \& Industry 17, 104 (2016)

Table 1. Physical properties of hBN nanoparticles.

\begin{tabular}{cc}
\hline${ }^{a}$ Properties & hBN nanoparticles \\
\hline Appearance & White powder \\
Average diameter particle size $(\mathrm{nm})$ & 70 \\
Density $\left(\mathrm{kg} \cdot \mathrm{m}^{-3}\right)$ & 2.3 \\
Maximum use temperature in air $\left({ }^{\circ} \mathrm{C}\right)$ & 1800 \\
Thermal conductivity $\left(\mathrm{W} \cdot \mathrm{m}^{-1} \cdot \mathrm{K}^{-1}\right)$ & 27 \\
Thermal Expansion Coefficient $@ 25{ }^{\circ} \mathrm{C}-1000{ }^{\circ} \mathrm{C}$ & $1 \times 10^{-6} /{ }^{\circ} \mathrm{C}$ (parallel to press dir.) \\
\hline
\end{tabular}

${ }^{\mathrm{a}}$ From manufacturer.

Table 2. Lubricating properties of SAE 15W-40 optimized nano-oil [15].

\begin{tabular}{ccc}
\hline${ }^{a}$ Properties & SAE 15W-40 & Optimized nano-oil \\
\hline Kinematic viscosity @ $40{ }^{\circ} \mathrm{C}, \mathrm{m}^{2} \cdot \mathrm{s}^{-1}$ & $1.06 \times 10^{-4}$ & $1.03 \times 10^{-4}$ \\
Kinematic viscosity @100 ${ }^{\circ} \mathrm{C}, \mathrm{m}^{2} \cdot \mathrm{s}^{-1}$ & $1.35 \times 10^{-5}$ & $1.44 \times 10^{-5}$ \\
Viscosity Index & 127 & 131 \\
Flash point temperature, ${ }^{\circ} \mathrm{C}$ & 218 & 218 \\
Total Base Number (TBN) & 7.38 & 9.58 \\
Total Acid Number (TAN) & 4.70 & 5.63 \\
\hline
\end{tabular}

${ }^{\mathrm{a}}$ From laboratory measurements.

In general, as observed from prior studies, there are a limited number of studies to investigate the potential of hBN nanoparticles as friction modifier and antiwear additive in engine oil. Hence, the goal of this paper is to find out if there exists a possibility for improving the tribological performance of conventional diesel engine oil using hBN nanoparticles additive. This promising technology has an even greater impact on fuel consumption and engine durability for a greener future.

\section{Experimental procedure}

\subsection{Nanoparticles material}

In this study, $70 \mathrm{~nm}$ size of hexagonal boron nitride (hBN) nanoparticle was used as an additive for tribological application of engine oil. The $\mathrm{hBN}$ is also known as "white graphite", has similar (hexagonal) crystal structure as of graphite. This crystal structure provides excellent lubricating properties due to low coefficient of friction. The physical properties of hBN nanoparticles are shown in Table 1.

\subsection{Sample preparation}

The sonication technique was used to prepare the nano-oil by dispersing an optimal composition ( 0.5 vol.\%) of $70 \mathrm{~nm}$ hBN nanoparticles in conventional diesel engine oil (SAE 15W-40), using an ultrasonic homogenizer for 20 min. The optimal composition was determined from the previous work [14]. Samples were stabilized using $0.3 \mathrm{vol} . \%$ of surfactant (oleic acid) to prevent sedimentation of nanoparticles. The surfactant shows no significant effect on the tribological performance of lubricants [15].

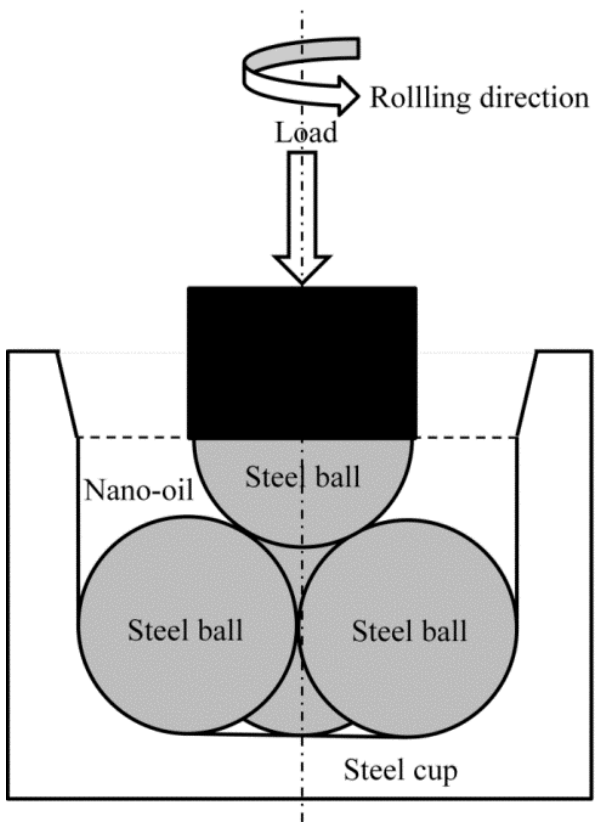

Fig. 1. Schematic diagram of a four-ball tribometer.

The lubricating properties of SAE $15 \mathrm{~W}-40$ and optimized nano-oil were measured from the previous work [16], as shown in Table 2.

\subsection{Tribological testing}

Tribological testing was performed to determine the friction coefficient and wear rate between the contact surfaces using a four-ball tribometer, as shown in Figure 1. The testing procedure followed the guidelines in ASTM Standard: D4172-94(2010) [17]. The speed, load, time, and temperature, were $1200 \mathrm{rpm}, 392.4 \mathrm{~N}, 3600 \mathrm{~s}$, and 
Table 3. Mechanical properties of the ball material.

\begin{tabular}{cc}
\hline${ }^{a}$ Properties & $\begin{array}{c}\text { Ball bearing } \\
\text { (Carbon chromium steel) }\end{array}$ \\
\hline Hardness $(H)$, HRC & 61 \\
Density $(\rho)$, g.cm & \\
Surface roughness $\left(R_{a}\right), \mu \mathrm{m}$ & 7.79 \\
\hline
\end{tabular}

${ }^{a}$ From laboratory measurements.

$75{ }^{\circ} \mathrm{C}$, respectively. The test was repeated three times to ensure that the results are more precise and reliable. The four-ball tribometer incorporated three $12.7 \mathrm{~mm}$ diameter carbon chromium steel balls, clamped together, and covered with lubricant for evaluation. A fourth steel ball of the same diameter (referred to as the top ball), held in a special collet inside a spindle, was rotated by an AC motor. The top ball was rotated in contact with the three fixed balls that were immersed in the sample oil. The coefficient of friction was recorded using a data terminal processing system. The wear scar diameter was measured by microscope. The detailed mechanical properties of the balls are shown in Table 3 .

The volume $(V)$ of the ball's worn material was estimated geometrically; using the basis of the radius of ball $(R)$, radius of the wear scar $(a)$ and its height $(h)$ using the following equations:

$$
\begin{aligned}
V & =\left(\pi h^{2} / 3\right)(3 R-h) \\
h & =R-\sqrt{R^{2}-a^{2}}
\end{aligned}
$$

The wear rate was then calculated using the following equation:

$$
\text { Wear rate }=V / t
$$

Where $t$ is a sliding time in unit s.

The minimum film thickness for a circular point contact, as formed in the four-ball tribometer machine is calculated by using the Elastohydrodynamic Lubrication (EHL) theory, developed by Hamrock and Dowson [18].

\subsection{Surface morphology observation}

The surface roughness of the worn surfaces was measured using a profilometer. Furthermore, the morphology of the nanoparticles and worn surfaces were observed using scanning electron microscopy (SEM). The chemical composition was determined using Energy-Dispersive X-ray spectroscopy (EDX).

\section{Results and discussion}

The present results are only focused on the frictionreduction and antiwear properties between the optimized nano-oil and conventional diesel engine oil. The detailed discussions on how to determine the optimal design parameters of nano-oil can be found in the previous works $[14,15]$.

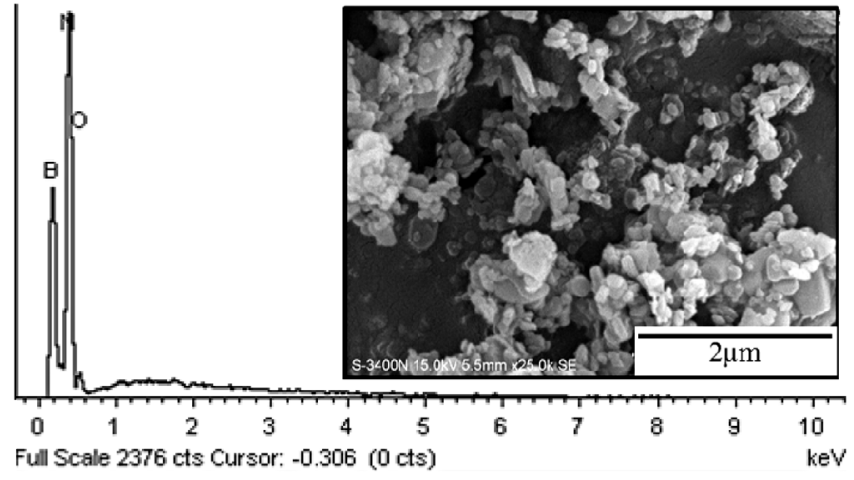

Fig. 2. EDX spectrum and SEM micrograph of hBN nanoparticles.

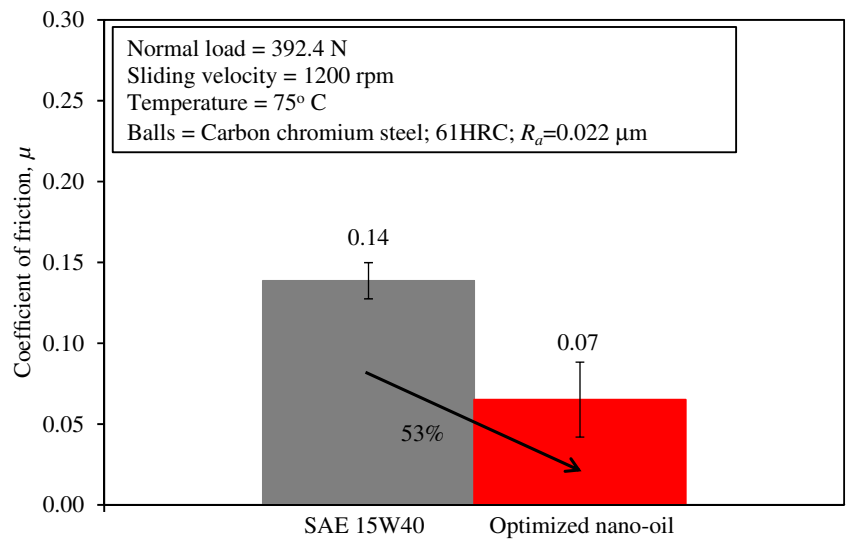

Fig. 3. Average steady state coefficient of friction between conventional diesel engine oil and optimized nano-oil.

\subsection{Nanoparticles characterization}

The EDX spectrum and SEM micrograph of hBN nanoparticles are shown in Figure 2. The hBN nanoparticles were in spherical type. The received particle size is $70 \mathrm{~nm}$ as mentioned by the manufacturer. However, the actual distribution of the particle sizes cannot be obtained due to the particles agglomeration.

\subsection{Lubrication regime}

Table 4 shows the lubrication regime for both conventional diesel engine oil and optimized nano-oil. Both samples present in boundary lubrication regime $(\lambda \leq 1)$. During the boundary lubrication regime, a constant contact between the friction surfaces at high surface point usually occurred. This situation usually will cause undesirable higher friction and wear rate. Although both lubricants are under boundary lubrication regime, the optimized nano-oil shows the greater film thickness ratio, as compared with conventional diesel engine oil.

\subsection{Friction-reduction property}

From Figure 3, the steady state friction coefficient of the optimized nano-oil decreased significantly by $53 \%$ 


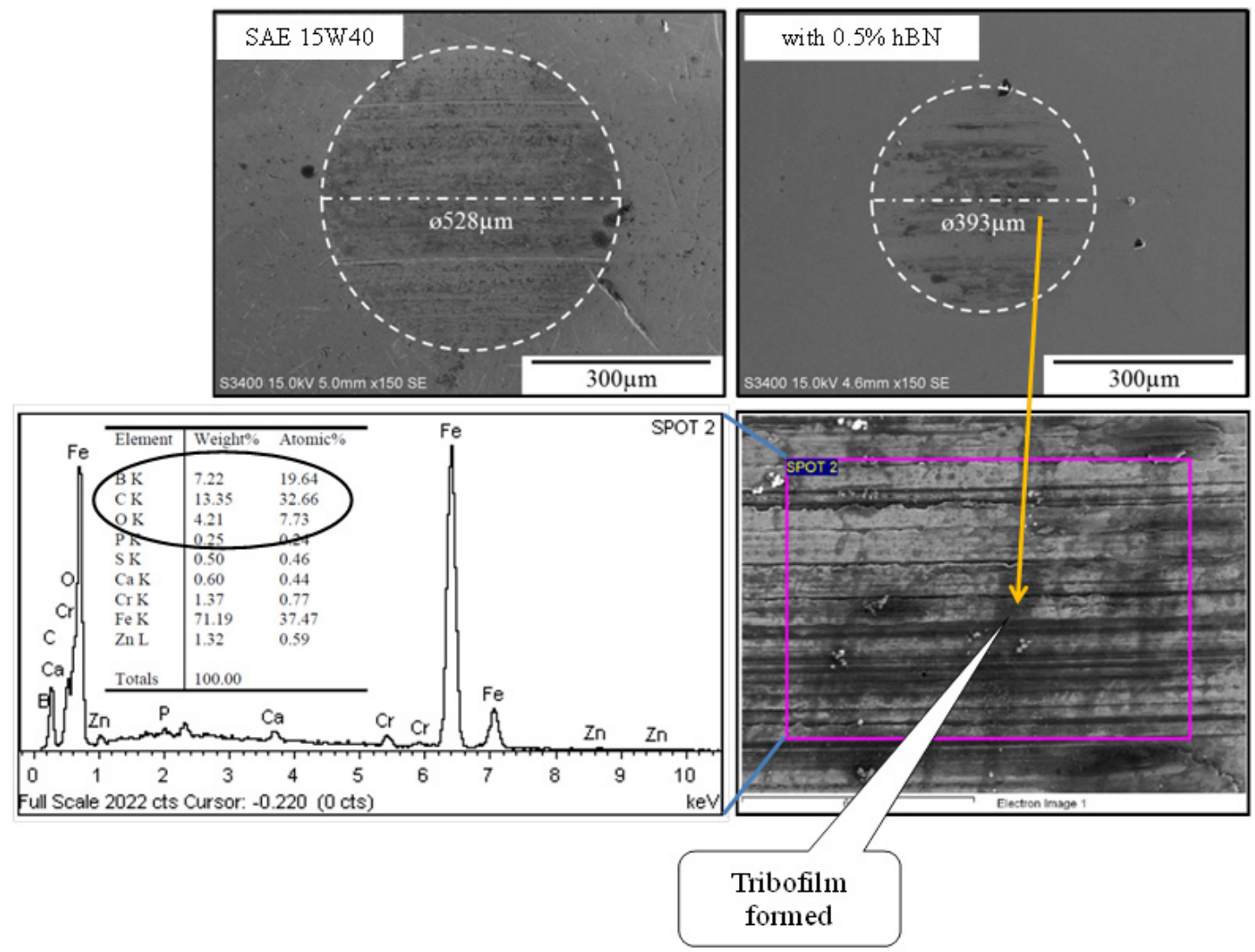

Fig. 4. The SEM micrograph and EDX spectrum shows the tribolfilm formation, mainly dominated by boron oxide elements, on the worn surfaces of the material lubricated by optimized nano-oil.

Table 4. Lubrication regime for both conventional diesel engine oil and optimized nano-oil.

\begin{tabular}{ccc}
\hline Properties & \multicolumn{2}{c}{ Sample } \\
\cline { 2 - 3 } & SAE 15W-40 & Optimized nano-oil \\
\hline Dimensionless minimum film thickness, $H_{\min }$ & 0.00337 & 0.00343 \\
Minimum film thickness, $h_{\min }(\mu \mathrm{m})$ & $1.07 \times 10^{-5}$ & $1.09 \times 10^{-5}$ \\
Film thickness ratio, $\lambda$ & 0.017605 & 0.143341 \\
Lubrication regime & Boundary & Boundary \\
\hline
\end{tabular}

for all three repeated tests, as compared with conventional diesel engine oil. The friction coefficient reduction is from about 0.14 to 0.07 . As sliding continues, it is clearly shown as in Figure 4 that tribochemical reactions took place (mainly dominated by boron, oxygen and carbon elements) due to the local high contact pressure and flash temperature caused by the collision and rupture of the asperities between the mating surfaces. It is believed that the generated tribofilm is boron oxide $\left(\mathrm{B}_{2} \mathrm{O}_{3}\right)$, which could potentially reduce the coefficient of friction of the mating surfaces.

In addition and from the view point of boundary lubrication, reducing friction coefficient may also be due to the higher calculated film thickness ratio, as shown in Table 4.

\subsection{Antiwear property}

Figure 5 shows the wear rate values calculated using Equation [7-9]. The optimized nano-oil reduced

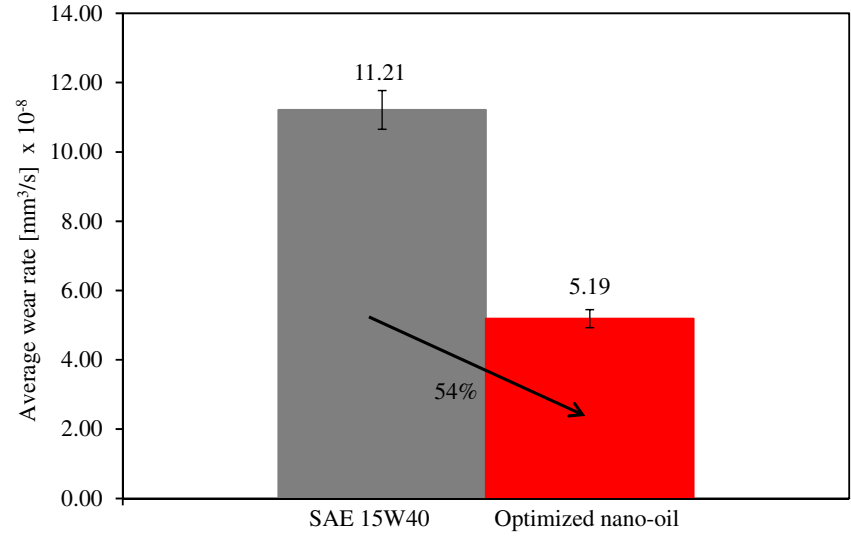

Fig. 5. Average wear rates of ball materials lubricated under conventional diesel engine oil and optimized nano-oil.

wear rate by approximately $54 \%$, which is half of the total wear gained by conventional diesel engine oil. 


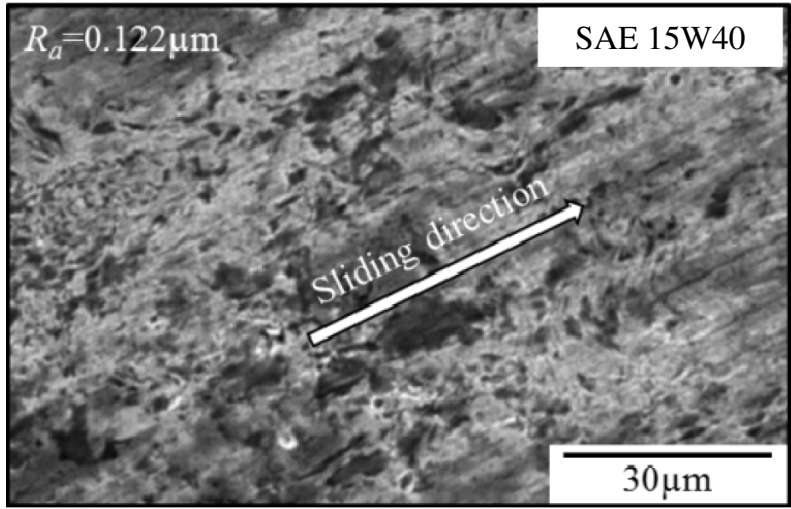

(a)

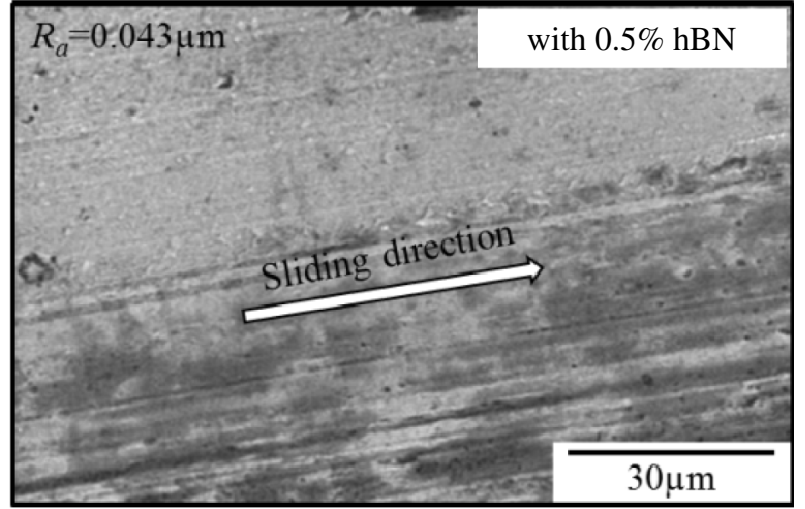

(b)

Fig. 6. SEM micrograph of the worn surfaces of the material lubricated by (a) conventional diesel engine oil and (b) optimized nano-oil.optimized nano-oil. $R_{a}$ is the arithmetic average surface roughness.

The wear rate reduction is from about $11.21 \times 10^{-9}$ to $5.19 \times 10^{-9} \mathrm{~mm}^{3} \cdot \mathrm{s}^{-1}$. This is in accordance with a significant reduction of friction coefficient (Fig. 3) and wear scar diameter (Fig. 4). These results are consistent with those of Baş and Karabacak [19], who found that the addition of boron compounds into lubrication oils decreased the coefficient of friction from 10 to $50 \%$.

From Figure 6, worn surfaces of the material lubricated by conventional diesel engine oil were characterized by adhesive wear and some abrasive wear. However, worn surfaces of the material lubricated by optimized nano-oil were characterized by slightly adhesive wear with smoother surfaces and show signs of fine scratches compared to the conventional diesel engine oil. A reduction in adhesion is directly responsible for the reduction in friction and wears [20]. These results agree with the calculated wear rate values (Fig. 5).

\section{Conclusions}

This paper presented results of hBN nanoparticles as potential friction modifier and antiwear additive in engine oil. In summary, the current study shows that the optimized nano-oil could reduce the coefficient of friction and increase wear resistance, as compared with conventional diesel engine. The friction reduction performance can be attributed to the boron oxide formed by tribochemical reactions and results in a significant reduction of wear rate. From the view point of boundary lubrication, reducing friction coefficient may also be due to the higher calculated film thickness ratio. Some adhesive and abrasive wear types were identified as predominant wear mechanisms.

Acknowledgements. The authors wish to thank Prof. Dr. Jaharah Binti A. Ghani who has helped for surface roughness measurement. The authors also gratefully acknowledge contributions from the members of the Green Tribology and Engine Performance (G-TriboE) research group. This research was supported by grants from the World Academy of Sciences (TWAS) grant number: GLUAR/2013/FKM(2)/ A00003], Ministry of Education Malaysia [grant numbers: FRGS/2013/FKM/TK01/02/1/ F00163 and FRGS/2013/FTK/TK06/02/3/F00166], and Universiti Teknikal Malaysia Melaka (UTeM) [grants number: PJP/2012/FKM(40A)/S01044 and PJP/2012/FKM(11A)/ S01086].

\section{References}

[1] M. Zhang, X. Wang, W. Liu, X. Fu, Performance and antiwear mechanism of $\mathrm{Cu}$ nanoparticles as lubricating oil additives, Ind. Lubr. Tribol. 61 (2009) 311-318

[2] Y.Y. Wu, W.C. Tsui, T.C. Liu, Experimental analysis of tribological properties of lubricating oils with nanoparticle additives, Wear 262 (2007) 819-825

[3] Z. Xiaodong, F. Xun, S. Huaqiang, H. Zhengshui, Lubricating properties of Cyanex 302-modified $\mathrm{MoS}_{2}$ microspheres in base oil 500SN, Lubr. Sci. 19 (2007) 71-79

[4] C. Novak, D. Kingman, K. Stern, Q. Zou, L. Gara, Tribological Properties of Paraffinic Oil with Nanodiamond Particles, Tribol. Trans. 57 (2014) 831-837

[5] Y. Hwang, C. Lee, Y. Choi, S. Cheong, D. Kim, K. Lee, J. Lee, S.H. Kim, Effect of the size and morphology of particles dispersed in nano-oil on friction performance between rotating discs, J. Mech. Sci. Technol. 25 (2011) 2853-2857

[6] S. Qiu, J. Dong, G. Chen, Z. Zhou, Preparation of Ni nanoparticles and evaluation of their tribological performance as potential additives in oils, J. Tribol. 123 (1999) $441-443$

[7] X. Tao, Z. Jiazheng, X. Kang, The ball-bearing effect of diamond nanoparticles as an oil additive, J. Phys. D 29 (1996) 2932-2937

[8] S. Chen, W. Liu, Oleic acid capped PbS nanoparticles: Synthesis, characterization and tribological properties, Mater. Chem. Phys. 98 (2006) 183-189

[9] S. Chen, W. Liu, Characteristic and antiwear ability of non-coated ZnS nanoparticles and DDP-coated ZnS nanoparticles, Mater. Res. Bull. 36 (2001) 137-143

[10] Z.F. Zhang, W.M. Liu, Q.J. Xue, The tribological behaviors of succinimide-modified lanthanum hydroxide 
nanoparticles blended with zinc dialkyldithiophosphate as additives in liquid paraffin, Wear 248 (2001) 48-54

[11] K. Lee, Y. Hwang, S. Cheong, Understanding the role of nanoparticles in nano-oil lubrication, Tribol. Lett. 35 (2009) 127-131

[12] F. Chiñas-Castillo, H.A. Spikes, Mechanism of action of colloidal solid dispersion, J. Tribol. 125 (2003) 552-557

[13] S. Chen, W. Liu, L. Yu, Preparation of DDP-coated PbS nanoparticles and investigation of the antiwear ability of the prepared nanoparticles as additive in liquid paraffin, Wear 218 (1998) 153-158

[14] M.I.H.C. Abdullah, M.F.B. Abdollah, H. Amiruddin, N. Tamaldin, N.R. Mat Nuri, Optimization of tribological performance of $\mathrm{hBN} / \mathrm{Al}_{2} \mathrm{O}_{3}$ nanoparticles as engine oil additives, Procedia Eng. 68 (2014) 313-319

[15] M.I.H.C. Abdullah, M.F.B. Abdollah, H. Amiruddin, N. Tamaldin, N.R. Mat Nuri, Effect of $\mathrm{hBN} / \mathrm{Al}_{2} \mathrm{O}_{3}$ nanoparticle additives on the tribological performance of engine oil, Jurnal Teknologi 66 (2014) 1-6
[16] M.I.H.C. Abdullah, M.F.B. Abdollah, H. Amiruddin, N. Tamaldin, N.R. Mat Nuri, M. Hassan, Rafeq, S.A. Rafeq, Effect of hBN/Al2O3Nanoparticles on Engine Oil Properties, Energy Education Science and Technology Part A 32 (2014) 3261-3268

[17] ASTM Standard: D 4172-94 (2010) Standard Test Method for Wear Preventive Characteristics of Lubricating Fluid (Four-Ball Method), www .astm.org

[18] B.J. Hamrock, D. Dowson, Ball Bearing Lubrication: The Elastohydrodynamics of Elliptical Contacts, Wiley, New York (1981)

[19] H. Baş, Y.E. Karabacak, Investigation of the effects of boron additives on the performance of engine oil, Tribol. Trans 57 (2014) 740-748

[20] C. Zhao, Y. Jiao, Y.K. Chen, G. ren., The Tribological Properties of Zinc Borate Ultrafine Powder as a Lubricant Additive in Sunflower Oil, Tribol. Trans. 57 (2014) $425-434$ 